\title{
Efficacy of Extramedullary Femoral Component Alignment Guide System for Blood Saving after Total Knee Arthroplasty
}

\author{
Suk Ha Jeon, MD, Ji Hun Kim, MD, Jung Myung Lee, MD, PhD and Eun Seok Seo, MD \\ Department of Orthopedic Surgery, National Medical Center, Seoul, Korea
}

\begin{abstract}
Purpose: To compare the extramedullary femoral alignment guide system with the conventional intramedullary alignment guide system for bleeding and transfusion rate after total knee arthroplasty (TKA).

Materials and Methods: Forty-nine female TKA patients were randomized into two groups: intramedullary (IM) group vs. extramedullary (EM) group. Drained volume of blood, hemoglobin concentration, hemoglobin drop, and transfusion rate were compared between the two groups. Wound problems, bleeding-related problems and thromboembolic complications were collected.

Results: The mean drained volume via vacuum drainage was less in the EM group than that in the IM group (482.9 $\mathrm{mL}$ vs. $266.8 \mathrm{~mL}$, p=0.001). Hemoglobin at 5 days after surgery was higher in the EM group $(9.3 \mathrm{~g} / \mathrm{dL}$ vs. $9.9 \mathrm{~g} / \mathrm{dL}, \mathrm{p}=0.002)$ than that in the IM group. The drop in hemoglobin after 5 days was smaller in the EM group $(3.5 \mathrm{~g} / \mathrm{dL}$ vs. $2.9 \mathrm{~g} / \mathrm{dL}, \mathrm{p}=0.003)$ than that in the IM group. The EM group had a lower prevalence of allogeneic transfusion ( $45.0 \%$ vs. $20.5 \%, \mathrm{p}=0.026)$ than that in the IM group. No significant complications developed in either group.

Conclusions: The results suggest that the extramedullary femoral alignment guide technique is an advantageous method that can reduce the drained volume of blood and the allogeneic transfusion rate.
\end{abstract}

Key words: Knee, Extramedullary femoral component alignment guide, Blood saving, Bleeding, Transfusion.

\section{Introduction}

Total knee arthroplasty (TKA) involves significant blood loss that may require a blood transfusion, which carries its own risks including transmission of infection, abnormal immunological responses, febrile transfusion reactions, and allergic reactions ${ }^{1,2)}$. Accordingly, continuous efforts have been made to avoid complications associated with allogeneic blood transfusion,

Received November 1, 2011; Revised December 4, 2011;

Accepted February 23, 2012.

Correspondence to: Eun Seok Seo, MD.

Department of Orthopedic Surgery, National Medical Center, 245, Euljiro, Jung-gu, Seoul 100-799, Korea.

Tel: +82-2-2260-7187, Fax: +82-2-2278-9570

Email: machine411@korea.com

This is an Open Access article distributed under the terms of the Creative Commons Attribution Non-Commercial License (http://creativecommons.org/licenses/by-nc/3.0/) which permits unrestricted non-commercial use, distribution, and reproduction in any medium, provided the original work is properly cited. which has led to the invention of blood saving strategies including preoperative autologous donation ${ }^{3-5)}$, treatment of preoperative anemia using oral iron therapy, subcutaneous drainage $^{6}$, drain clamping ${ }^{7)}$, and hypotensive anesthesia ${ }^{8)}$. Lower extremity alignment is one of the paramount factors determining the long-term success of TKA ${ }^{9-11)}$. A satisfactory alignment can be obtained with the use of a intramedullary or extramedullary alignment guide system. In particular, extramedullary guides are preferred for the tibial side and intramedullary guides are preferred for the femoral side. Unfortunately, the use of an intramedullary guide for the femur has been associated with increased risks of fat embolism, blood loss, postoperative hypoxia, and intraoperative fractures ${ }^{12-14}$. Despite the clinical advantages offered by the extramedullary femoral alignment system, it has been employed in limited circumstances to obtain optimal postoperative alignment and avoid technical challenges. However, TKAs using extramedullary femoral alignment guides have been extensively studied in recent years. Kalairajah et al. ${ }^{15}$ reported the results of navigation-assisted TKAs and Seo et al. ${ }^{16)}$ introduced a new extramedullary guide that aligns the femoral component exactly with the coronal, sagittal, and rotational axes. 
The purpose of this study was to investigate whether the extramedullary femoral alignment system is advantageous over the traditional intramedullary system in terms of blood loss and transfusion after TKA. Our hypothesis is that the extramedullary system will result in less blood loss and fewer transfusions.

\section{Materials and Methods}

This study included 80 female patients who underwent unilateral TKA under the diagnosis of degenerative arthritis between October 2010 and September 2011 at our institution. Exclusion criteria were a diagnosis other than degenerative arthritis, anticoagulation therapy, liver failure, and renal failure. The enrolled patients were randomized into a extramedullary (EM) group $(n=40)$ and a intramedullary (IM) group $(n=40)$. Excluding one patient in the EM group in whom internal fixation was required due to an intraoperative fracture, the remaining 79 patients were included for analysis. No intergroup differences were observed in age, weight, height, body mass index, or preoperative hemoglobin concentration (Table 1).

The surgical protocol was the same for both groups, besides the type of the alignment guide for the distal femoral resection (extramedullary/intramedullary). In particular, all patients received epidural and spinal anesthesia and the preoperative and postoperative procedures and surgical techniques were identical. Patient-controlled analgesia was implemented postoperatively using a $100 \mathrm{~mL}$ mixture of $90 \mathrm{~mL}$ of $0.125 \%$ bupivacaine and 0.5 $\mathrm{mg} / 10 \mathrm{~mL}$ fentanyl via an epidural catheter. All operations were performed by the same surgeon (first author) using a medial parapatellar approach introduced by Insall. The posterior cruciate ligament (PCL) was removed and the same PCL-sacrificing prosthesis (Scorpio NRG, Stryker, Kalamazoo, MI, USA) was implanted in all knees. The patella was replaced, and the prosthetic components were cemented in all cases. Lateral release was not performed in all patients. Two markers indicating the

Table 1. Comparison of the Demographic Data between the Intramedullary (IM) and the Extramedullary (EM) Groups ${ }^{\text {a) }}$

\begin{tabular}{lccc}
\hline \multicolumn{1}{c}{ Variable } & IM $(\mathrm{n}=40)$ & EM $(\mathrm{n}=39)$ & $\begin{array}{c}\text { Significance } \\
(\mathrm{p} \text {-value })\end{array}$ \\
\hline Age $(\mathrm{yr})$ & $69.2(6.7)$ & $70.1(8.2)$ & 0.612 \\
Body weight $(\mathrm{kg})$ & $63.6(10.3)$ & $62.7(7.9)$ & 0.594 \\
Body height $(\mathrm{cm})$ & $152.8(6.8)$ & $151.9(5.7)$ & 0.748 \\
Body mass index $\left(\mathrm{kg} / \mathrm{m}^{2}\right)$ & $27.1(3.8)$ & $26.8(2.5)$ & 0.655 \\
Preoperative $\mathrm{Hb}(\mathrm{g} / \mathrm{dL})$ & $12.8(0.6)$ & $12.9(0.9)$ & 0.754 \\
\hline
\end{tabular}

${ }^{\text {a) }}$ Values are presented as means with standard deviations in parentheses. center of the femoral head and the anterior margin of the greater trochanter were firmly attached to the patient's skin in the EM group prior to surgery so the surgeon could palpate the markers and identify the mechanical axis of the lower limb during surgery. A femoral cutting block was aligned along the coronal and axial axes using new surgical equipment ${ }^{16)}$ and the two markers. The distal femur was cut without placing a rod into the medullary canal (Fig. 1). The angle between the anatomical axis and the mechanical axis of the femur in the IM group was measured using a PACS system on a preoperative anterioposterior long leg standing radiograph. An intramedullary alignment rod was inserted based on the preoperative measurements, and the distal femur was cut. The entrance hole for the alignment rod in the femoral medullary canal was sealed with bone fragments before inserting the implant. An extramedullary alignment guide was used in both groups for proximal tibial cutting. A drainage tube was placed in the intra-articular space. After wound closure, a compression dressing using gauze and a bandage was applied, and the tourniquet was deflated. Drainage was discontinued from immediately after surgery until 2 hours after tourniquet deflation. All drains were removed 24 hours after surgery. Blood transfusion was performed when hemoglobin was $<8$ $\mathrm{g} / \mathrm{dL}$ or when dyspnea, palpitation, dizziness, or abnormal vital signs were noted even if the hemoglobin was $8-10 \mathrm{~g} / \mathrm{dL}$. Rivaroxaban, an oral anticoagulant, was administered from immediately after the drain removal until the postoperative week 2 to prevent thromboembolic disorders. The anticoagulant was discontinued if hemarthrosis due to intra-articular bleeding was present or effusion from the surgical wound continued. Tests for thromboembolic disorders were not performed unless clinical symptoms appeared.

Statistical analyses were conducted using SPSS ver. 12.0 (SPSS Inc., Chicago, IL, USA). A p-value $<0.05$ was considered

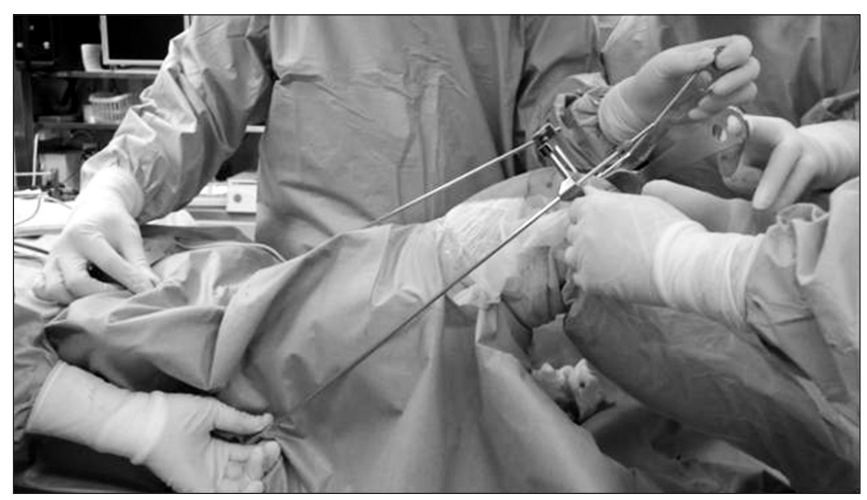

Fig. 1. Placing the distal femoral block to match the coronal and sagittal plane of the femur. 
statistically significant. The continuous variables, drained blood volume and preoperative hemoglobin level, were analyzed using Student's $t$-test. The hemoglobin level at 5 days after surgery and the hemoglobin drop (hemoglobin level at 5 days after surgeryhemoglobin level before surgery) were compared between groups using analysis of covariance. The prevalence of allogeneic transfusion, a categorical variable, was compared between the groups using Fisher's exact test. Additionally, the presence of other related symptoms were also investigated, including the duration of effusion, subcutaneous hematomas, hemarthrosis, hemorrhagic complications such as infections, painful leg swelling, acute chest pain, dyspnea, lower limb thrombosis, and pulmonary embolism.

\section{Results}

The mean drained volume via vacuum drainage was significantly less in the EM group compared to that in the IM group $(266.8 \pm 164.1 \mathrm{~mL}$ vs. $482.9 \pm 323.3 \mathrm{~mL})(\mathrm{p}=0.001)$. The mean hemoglobin at 5 days after surgery was significantly higher in the EM group compared to that in the IM group $(9.9 \mathrm{~g} / \mathrm{dL}$ vs. $9.3 \mathrm{~g} / \mathrm{dL})(\mathrm{p}=0.002)$. The hemoglobin drop at 5 days after surgery was notably lower in the EM group compared to that in the IM group ( $2.9 \mathrm{~g} / \mathrm{dL}$ vs. $3.5 \mathrm{~g} / \mathrm{dL})(\mathrm{p}=0.003)$. The prevalence of allogeneic transfusion was remarkably lower in the EM group compared to that in the IM group ( 8 in 39 patients, $20.5 \%$ vs. 18 in 40 patients, $45 \%)(\mathrm{p}=0.026)$ (Table 2). The transfusion was prophylactic in five in the IM group and in two in the EM group. A transfusion was required in one patient with a hemoglobin level $\geq 8 \mathrm{~g} / \mathrm{dL}$ in each group due to complaints of dizziness.

No severe complications occurred in either group. Anticoagulation therapy was discontinued due to continuous effusion from the surgical wound in two patients in the IM group, but they recovered without further complications after discontinuation. Thromboembolic disorders were not observed in any of the patients.

\section{Discussion}

TKA is commonly performed in elderly patients and substantial blood loss during TKA can result in increased risks and disruption of recovery in patients with poor systemic condition $^{17,18)}$. Accordingly, a blood transfusion is often required after TKA. In an attempt to reduce the adverse effects of blood transfusion, many studies have provided various methods, including preoperative autologous donation ${ }^{3-5)}$, use of the call saver $^{19)}$ and fibrinogen concentrates ${ }^{20)}$, subcutaneous suction drainage $^{6)}$, drain clamping ${ }^{7)}$, hypotensive anesthesia ${ }^{8)}$, and other methods ${ }^{17-211}$.

In this study, the EM group had more favorable results than those in the IM group in terms of blood savings. The mean drained volume via the vacuum drainage was smaller in the EM group, hemoglobin at 5 days after surgery was higher, the hemoglobin drop was smaller, and the prevalence of allogeneic transfusion was lower. These results are congruent with the hypothesis that the extramedullary alignment guide system reduces blood loss and transfusion rate. In this study, we measured blood volume drained via vacuum drainage and the hemoglobin but did not calculate the blood loss based on some reports ${ }^{22,23)}$ in which the measured blood loss reflects calculated blood loss. The extramedullary alignment guide system and intramedullary alignment guide system have been compared in terms of blood loss in many studies. In 2005, Kalairajah et al. ${ }^{15}$ reported that mean blood drainage volume was significantly smaller in the group in which a computer-assisted technique was used compared to that in the control group $(1,351 \mathrm{~mL}$ vs. 1,747 mL). In 2006, Kandel et al. ${ }^{14)}$ documented that mean blood drainage volume was significantly lower in a extramedullary guide system group compared to that in a intramedullary guide system group (613 mL vs. $758 \mathrm{~mL}$ ), and transfusion volume appeared to be less in the former group. Our results were comparable with those of other studies ${ }^{14,15,24,25)}$ that showed blood loss could be reduced by $145-396 \mathrm{~mL}$ when the medullary canal was not breached during TKA. Although the frequency

Table 2. Comparisons of the Hematological Data between the Intramedullary (IM) and Extramedullary (EM) Groups ${ }^{\text {a) }}$

\begin{tabular}{lccc}
\multicolumn{1}{c}{ Variable } & IM $(\mathrm{n}=40)$ & EM $(\mathrm{n}=39)$ & Significance $(\mathrm{p}$-value $)$ \\
\hline Hemovac drainage $(\mathrm{mL})$ & $482.9(323.3)$ & $266.8(164.1)$ & 0.001 \\
Hb at postoperative day 5 $(\mathrm{g} / \mathrm{dL})$ & $9.3(0.7)$ & $9.9(1.2)$ & 0.002 \\
Hb drop after 5 days $(\mathrm{g} / \mathrm{dL})$ & $3.5(0.9)$ & $2.9(1.1)$ & 0.003 \\
Allogeneic blood transfusion & $45.0 \%(18)$ & $20.5 \%(8)$ & 0.026 \\
\hline
\end{tabular}

${ }^{\text {a) } V a l u e s}$ are presented as means with standard deviations in parentheses except allogeneic blood transfusion, for which values are presented as percents and numbers (in parentheses) of patients who had the conditions. 
of transfusion was lower in the EM group in our study, it was still higher compared to some recent studies ${ }^{4,6)}$. We attributed this to the broad indications for transfusion we set in this study; a blood transfusion was performed when hemoglobin was $<8 \mathrm{~g} / \mathrm{dL}$ or when dyspnea, palpitation, dizziness, or abnormal vital signs were noted, even if the hemoglobin was $8-10 \mathrm{~g} / \mathrm{dL}$. In addition, prophylactic transfusions that were carried out considering the patient's history of illness were counted in the transfusion rate calculation. However, when these prophylactic cases ( 5 in the IM group and 2 in the EM group) were not counted as transfusions, the frequency decreased to $37.1 \%$ (13 in 35 patients) in the IM group and $16.2 \%$ (6 in 37 patients) in the EM group. Furthermore, if a higher transfusion threshold of $7 \mathrm{~g} / \mathrm{dL}$ hemoglobin was set, the frequency would have declined to $27.5 \%$ (11 in 40 patients) in the IM group and to $5.1 \%$ ( 2 in 39 patients) in the EM group. A limitation of this study was the lack of diversity in the study population. We think that it would be difficult to extrapolate our findings to other patient groups, considering that our data were obtained only from female patients with a diagnosis of degenerative arthritis. Additionally, we did not assess intergroup differences regarding fat embolisms or postoperative complications, including hypoxia, pain, or lower limb alignment accuracy.

The intramedullary femoral alignment guide system can result in various complications and may not be applicable when a long-stemmed femoral component implanted during a previous surgery remains or a rod cannot be inserted due to severe deformity of the femur ${ }^{26}$. It has not been clearly elucidated which system is more advantageous over the other regarding component alignment accuracy. However, some recent studies have introduced techniques to improve the accuracy of the extramedullary alignment guide system ${ }^{16,27-30)}$. Therefore, we believe that the extramedullary alignment guide system could be useful for decreasing blood loss and transfusion frequency during TKA unless it is inferior to the intramedullary system in terms of component alignment accuracy.

\section{Conclusions}

We believe the extramedullary alignment guide system can be effective for reducing blood loss and transfusion rate after TKA.

\section{References}

1. Curran JW, Lawrence DN, Jaffe H, Kaplan JE, Zyla LD, Chamberland M, Weinstein R, Lui KJ, Schonberger LB,
Spira TJ. Acquired immunodeficiency syndrome (AIDS) associated with transfusions. N Engl J Med. 1984;310:69-75.

2. Conrad ME. Diseases transmissible by blood transfusion: viral hepatitis and other infectious disorders. Semin Hematol. 1981;18:122-46.

3. Bottner F, Pavone V, Johnson T, Heitkemper S, Sculco TP. Blood management after bilateral total knee arthroplasty. Clin Orthop Relat Res. 2003;(410):254-61.

4. Kourtzis N, Pafilas D, Kasimatis G. Blood saving protocol in elective total knee arthroplasty. Am J Surg. 2004;187:261-7.

5. Couvret C, Laffon M, Baud A, Payen V, Burdin P, Fusciardi J. A restrictive use of both autologous donation and recombinant human erythropoietin is an efficient policy for primary total hip or knee arthroplasty. Anesth Analg. 2004; 99:262-71.

6. Seo ES, Yoon SW, Koh IJ, Chang CB, Kim TK. Subcutaneous versus intraarticular indwelling closed suction drainage after TKA: a randomized controlled trial. Clin Orthop Relat Res. 2010;468:2168-76.

7. Yamada K, Imaizumi T, Uemura M, Takada N, Kim Y. Comparison between 1-hour and 24-hour drain clamping using diluted epinephrine solution after total knee arthroplasty. J Arthroplasty. 2001;16:458-62.

8. Tenholder M, Cushner FD. Intraoperative blood management in joint replacement surgery. Orthopedics. 2004;27: s663-8.

9. Jonsson B, Astrom J. Alignment and long-term clinical results of a semiconstrained knee prosthesis. Clin Orthop Relat Res. 1988;(226):124-8.

10. Ritter MA, Faris PM, Keating EM, Meding JB. Postoperative alignment of total knee replacement. Its effect on survival. Clin Orthop Relat Res. 1994;(299):153-6.

11. Tew M, Waugh W. Tibiofemoral alignment and the results of knee replacement. J Bone Joint Surg Br. 1985;67:551-6.

12. Fahmy NR, Chandler HP, Danylchuk K, Matta EB, Sunder $\mathrm{N}$, Siliski JM. Blood-gas and circulatory changes during total knee replacement. Role of the intramedullary alignment rod. J Bone Joint Surg Am. 1990;72:19-26.

13. Ishii Y, Ohmori G, Bechtold JE, Gustilo RB. Extramedullary versus intramedullary alignment guides in total knee arthroplasty. Clin Orthop Relat Res. 1995;(318):167-75.

14. Kandel L, Vasili C, Kirsh G. Extramedullary femoral alignment instrumentation reduces blood loss after uncemented total knee arthroplasty. J Knee Surg. 2006;19:256-8.

15. Kalairajah Y, Simpson D, Cossey AJ, Verrall GM, Spriggins AJ. Blood loss after total knee replacement: effects of computer- 
assisted surgery. J Bone Joint Surg Br. 2005;87:1480-2.

16. Seo JG, Moon YW, Kim YS. A comparison of extramedullary and intramedullary femoral component alignment guide systems in TKA. J Korean Knee Soc. 2006;18:47-54.

17. Berman AT, Geissele AE, Bosacco SJ. Blood loss with total knee arthroplasty. Clin Orthop Relat Res. 1988:137-8.

18. de Haan J, Boonstra PW, Monnink SH, Ebels T, van Oeveren W. Retransfusion of suctioned blood during cardiopulmonary bypass impairs hemostasis. Ann Thorac Surg. 1995;59:901-7.

19. Semkiw LB, Schurman DJ, Goodman SB, Woolson ST. Postoperative blood salvage using the Cell Saver after total joint arthroplasty. J Bone Joint Surg Am. 1989;71:823-7.

20. Marmor L, Avoy DR, McCabe A. Effect of fibrinogen concentrates on blood loss in total knee arthroplasty. Clin Orthop Relat Res. 1991;(273):136-8.

21. Healy WL, Pfeifer BA, Kurtz SR, Johnson C, Johnson W, Johnston R, Sanders D, Karpman R, Hallack GN, Valeri CR. Evaluation of autologous shed blood for autotransfusion after orthopaedic surgery. Clin Orthop Relat Res. 1994;(299):539.

22. Cushner FD, Friedman RJ. Blood loss in total knee arthroplasty. Clin Orthop Relat Res. 199;(269):98-101.

23. Levy AS, Marmar E. The role of cold compression dressings in the postoperative treatment of total knee arthroplasty. Clin Orthop Relat Res. 1993;(297):174-8.

24. Chauhan SK, Scott RG, Breidahl W, Beaver RJ. Computerassisted knee arthroplasty versus a conventional jig-based technique. A randomised, prospective trial. J Bone Joint Surg Br. 2004;86:372-7.

25. Dutton AQ, Yeo SJ, Yang KY, Lo NN, Chia KU, Chong HC. Computer-assisted minimally invasive total knee arthroplasty compared with standard total knee arthroplasty. A prospective, randomized study. J Bone Joint Surg Am. 2008;90:2-9.

26. Yoo JH, Han DY, Han CD, Lee YT, Oh HC, Ha JW, Park Y. Intramedullary and extramedullary combined alignment system for tibial component placement in total knee arthroplasty. J Korean Knee Soc. 2004;16:118-24.

27. Bathis H, Perlick L, Tingart M, Luring C, Zurakowski D, Grifka J. Alignment in total knee arthroplasty. A comparison of computer-assisted surgery with the conventional technique. J Bone Joint Surg Br. 2004;86:682-7.

28. Saragaglia D, Picard F, Chaussard C, Montbarbon E, Leitner F, Cinquin P. Computer-assisted knee arthroplasty: comparison with a conventional procedure. Results of 50 cases in a prospective randomized study. Rev Chir Orthop Reparatrice Appar Mot. 2001;87:18-28.

29. Seon JK, Song EK. The accuracy of lower extremity alignment in a total knee arthroplasty using computer-assisted navigation system. J Korean Orthop Assoc. 2004;39:566-71.

30. Sparmann M, Wolke B, Czupalla H, Banzer D, Zink A. Positioning of total knee arthroplasty with and without navigation support. A prospective, randomised study. J Bone Joint Surg Br. 2003;85:830-5. 